\title{
Study on Electric Vehicles and Communication Technologies in Smart Grid Environment
}

\author{
Sunguk Lee \\ Multimedia Engineering Department, Hannam University \\ 133 Ojeong-dong, Daeduk-gu, Daejeon, Korea \\ sulee0612@hnu.kr
}

\begin{abstract}
With rapid development of Electric vehicle technology market of EV has been expanded dramatically in past years. The conventional internal combustion engine vehicles uses fossil fuel while EV uses electric power from battery. Therefore EV emits no $\mathrm{CO}_{2}$ and pollutants and has higher efficiency. However EV has still problems to solve of high cost, short driving range and lack of charging station. Beside of these advantages a new role of $E V$ as distributed energy storage has been proposed. This scheme is referred as Vehicle to Grid (V2G). To support V2G and smart charging for EV exchange of information between $E V$ and power grid is necessary. This paper represents introduction of technologies for EV and EV charging infrastructure. Also communication technologies and standards for V2G interface and smart grid are also discussed.
\end{abstract}

Keywords: Electric Vehicle, Smart Grid, Battery, Charging Infrastructure, Vehicle to Grid

\section{Introduction}

The problems of depletion of fossil fuel resources, environmental pollution and low efficiency of legacy power system have been discussed widely at industry and academia recently. Many researchers have tried to utilize renewable energy resources like as solar and wind power to resolve these problems. Currently several countries have conducted many projects that optimize energy efficiency by exchanging real-time information between power suppliers and consumers and adaptation of renewable power resources.

This smart power grid called Smart Grid [1,2] adopts Intelligent Communication Technology (ICT) and renewable power generating resources at legacy power networks. Example of smart grid architecture is shown at Figure1. Due to unstable power generation with renewable power resources affected by environmental factors like as wind speed, sunshine and temperature, several weaknesses of smart grid such as power failure or deterioration of power quality should be overcome when using existing power networks. The ESS (Energy Storage System) can help to adapt the power generation to power consumption with help of bidirectional communication between power load and supplier. Also smart metering, energy monitoring and management technology can help to use smart grid at real world.

Another global trend to resolve the problem of environmental pollution is the development and expansion of electric vehicles in the automobile industry. Until now almost transportations have used fossil fuel such as gasoline and the numbers of automobiles have been increase dramatically. The use of huge fossil fuels produces great amount of carbon dioxide, which causes global warming. Therefore, the development of electric vehicle (EV) using electricity polluting-free power

Received (October 18, 2017), Review Result (December 12, 2017), Accepted (December 28, 2017) 
source has been becoming highlighted in many countries to reduce carbon emissions. France and the United Kingdom announced they will prohibit all sales of gasoline and diesel vehicles from 2040. Netherland has announced plans to ban the sale of internal combustion engines vehicles from 2030. Also Norway which has highest utilization rate of EVs in Europe will stop the sale of internal combustion engine vehicles from 2025. Other countries like as USA and Japan support customer financially and build infrastructure to promote utilization of EVs.

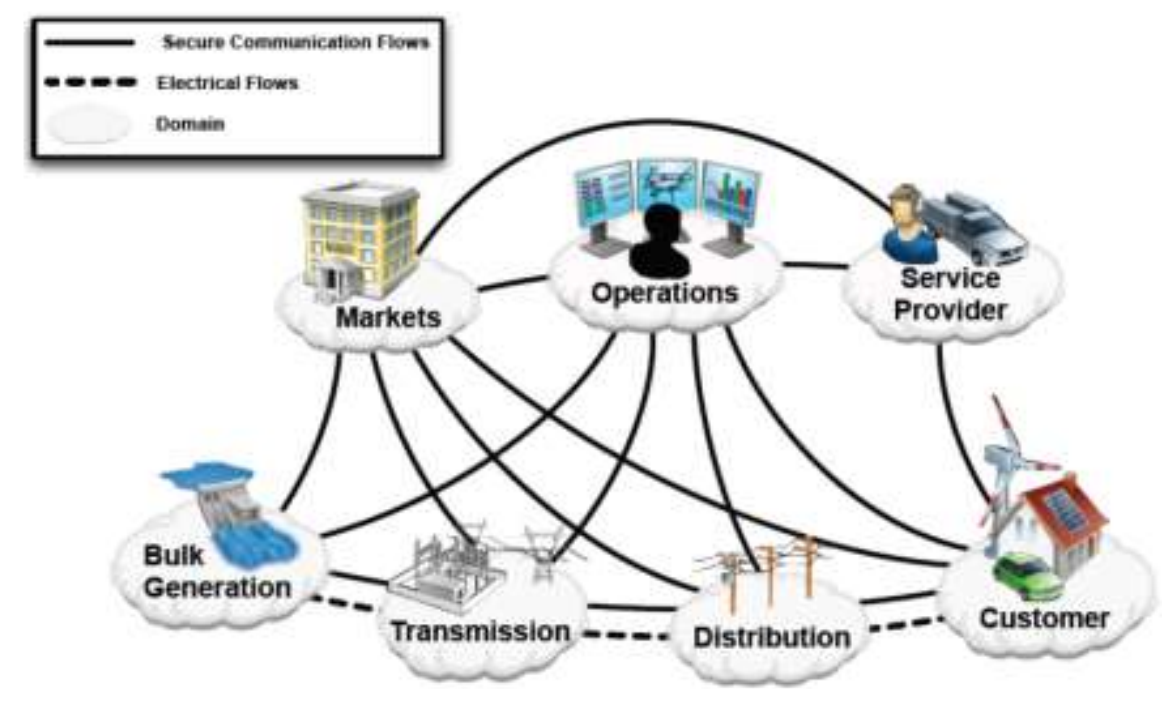

Figure 1. Smart Grid Conceptual Model by NIST [3]

In this paper we focus on technologies for $\mathrm{EV}$ and communication for $\mathrm{V} 2 \mathrm{G}$ and Smart Grid. The remainder of the paper is organized as follows. In the following section the overview of EV and EV charging infrastructure are described. Section 3 explains communication technologies for EV charging infrastructure. Section 4 concludes this paper.

\section{Technology for EV and Infrastructure for Charging Service}

As there is no combustion process for electric vehicles which use electric motor, the EVs exhaust no pollutant including carbon dioxide. Also the EVs are more efficient than conventional vehicles with internal combustion engine. However the price of EV [4] are expensive than existing internal combustion engines vehicles because of high battery cost. Due to limited capacity of battery EV have short driving distance with single charge [5]. Furthermore charging time for EVs is very long compared to traditional internal combustion engine vehicles. Therefore it is imperative to build and spread a charging infrastructure to solve the problem of the short driving distance of EVs. Also technology for battery should be developed for reducing cost and time for charging and improving capability. As mentioned above many countries support financially for customer who buy the EVs and promote to build EV charging infrastructure promptly.

\subsection{Technology for Electric Vehicle}

Electric Vehicle has made remarkable progress in many fields in recent decade. The Hybrid Electric Vehicle (HEV) were popular in the beginning, but today the majority of vehicle manufacturers are introducing externally powered EV such as Plug-in Hybrid Electric Vehicle(PHEV) and Plug -in Electric Vehicle(PEV) to the 
market. The market of PEV has been expanded rapidly with support from government. The EVs use electric motor for power train instead of conventional internal combustion engine. The EV has four components which are not used at internal combustion engine vehicle as bellows.

- Electric Motor

- Battery

- Inverter/Converter

- Battery Management System(BMS)

The Electric Motor generates driving force with electric power from battery and the Inverter/Converter works for conversion of direct and alternating current. The battery stores electric power and affects the biggest influence on the cost and performance of electric vehicles. The BMS is system that monitors and manages battery for controlling charge and discharge of battery. Table 1 shows characteristics of EVs [6].

Table 1. Characteristics of Commercial EVs

\begin{tabular}{cccccc}
\hline Model & Year & $\begin{array}{c}\text { Range } \\
(\mathrm{KM} / \text { charge })\end{array}$ & $\begin{array}{c}\text { Peak } \\
\text { Power } \\
(\mathrm{Kw})\end{array}$ & $\begin{array}{c}\text { Peak Torque } \\
(\mathrm{Nm})\end{array}$ & $\begin{array}{c}\text { Battery } \\
\text { Capacity(kWh) }\end{array}$ \\
\hline $\begin{array}{c}\text { Chevy Volt } \\
\text { EV }\end{array}$ & 2017 & 383 & 150 & 350 & 60 \\
VW E-Golf & 2017 & 300 & 100 & 290 & 35.8 \\
Hyundai Ionic & 2016 & 200 & 88 & 295 & 28 \\
BMW i3 & 2014 & 183 & 125 & 250 & 33.2 \\
Kia Soul EV & 2014 & 150 & 81.4 & 285 & 30 \\
Fiat 500e & 2013 & 135 & 83 & 199 & 24 \\
Benz B250-e & 2013 & 140 & 130 & 340 & 28 \\
\hline
\end{tabular}

Though EVs cannot guarantee long driving distance there are several advantages of using EVs. These advantages [7] comparing with conventional vehicles using fossil fuel can be described as follows.

- EV can reduce consumption of fossil fuel and mitigate energy dependency from oil

- With electric power generation from renewable resources EV can reduce Green House Gas (GHG).

- The cost per mile is much cheaper than that of internal combustion engine vehicle. EV is more efficient.

- The battery in EV can be considered as power storage. Therefore this concept can help to strength stability of smart grid.

However high cost of EV and short driving range should be resolved to expand market of EVs.

\subsection{Infrastructure for Charging EVs}

The EVs get electric power from exterior power grid and charge the onboard battery. The outside electric power is alternating current (AC) and battery uses direct current (DC). The charger for EV should rectify AC power from external power grid to supply appropriate DC power to battery for charging. Another anxiety of EV user except driving rage is charging time. The charging for EV can be classified as AC charging and DC charging. AC charging takes much time comparing with DC charging because of rectifying process to convert AC to DC. Each charging scheme also divided as 3 levels depending on charging power. Table 2 shows charging classification by society of automotive engineers (SAE) [8]. 
Table 2. Charging Standards by SAE

\begin{tabular}{|c|c|c|}
\hline Charging level & Charging Rating & $\begin{array}{l}\text { Charging Time } \\
\text { (SOC } 20 \% \text { to full) }\end{array}$ \\
\hline AC level 1 & $\begin{array}{l}120 \mathrm{~V}, 1.4 \mathrm{~kW}(12 \mathrm{~A}) \\
120 \mathrm{v}, 1.9 \mathrm{~kW}(16 \mathrm{~A})\end{array}$ & $17 \mathrm{~h}$ \\
\hline Ac level 2 & $240 \mathrm{~V}, \sim 19.2 \mathrm{~kW}(80 \mathrm{~A})$ & $\begin{array}{l}\text { For } 3.3 \mathrm{~kW} \text { charger : } 7 \mathrm{~h} \\
\text { For } 7 \mathrm{~kW} \text { charger }: 3.5 \mathrm{~h} \\
\text { For } 20 \mathrm{~kW} \text { charger }: 1.2 \mathrm{~h}\end{array}$ \\
\hline AC level 3 & $>20 \mathrm{~kW}$, single and three-phase & To be determined \\
\hline DC level 1 & $200-450 \mathrm{~V}_{\mathrm{DC}}$, up to $36 \mathrm{~kW}(80 \mathrm{~A})$ & For $20 \mathrm{~kW}$ charger : $1.2 \mathrm{~h}$ \\
\hline DC level 2 & $200-450 \mathrm{VDC}$, up to $90 \mathrm{~kW}(200 \mathrm{~A})$ & For $45 \mathrm{~kW}$ charger : $20 \mathrm{~min}$ \\
\hline DC level 3 & $\begin{array}{c}200-600 \text { VDC, up to } 240 \mathrm{~kW} \\
(400 \mathrm{~A})\end{array}$ & $\begin{array}{c}\text { For } 45 \mathrm{~kW} \text { charger }:<10 \\
\text { min }\end{array}$ \\
\hline
\end{tabular}

The fast charging scheme with DC power is the most effective and efficient scheme. The charging with DC level 3 scheme takes very short time to charge the battery compared to the charging with AC power.

The infrastructure for EV charging is expected to be adopted at Smart Grid $[9,10]$. The user can charge EV at home or dedicated charging station. To use of charging service many information should be exchanged between EV and Smart Grid through communication network. The AMI (Advanced Metering Infrastructure) can be used for communication between EV charger and central coordinator of Smart Grid. However more appropriate communication technologies are needed to exchange more sophisticated information among EV, power grid and coordinator of EV charging. The infrastructure for EV charging can be described as three major components as bellows.

- Charging Station

- Power Supply System

- Charging Infrastructure Operator.

The charging facility can be located in EV (on board charger) or dedicated location (off board charger). With on board charger EV can be charged at any place like as residence area through smart meter. This case AMI can be used for communication with grid however meaningful information of EV cannot deliver to power grid. The charging station for EV located at dedicated spot can have function of bidirectional communication with EV and charging infrastructure operator. Charging information of EV such as battery SOC (state of charge) and EV's ID may be delivered to charging station. The smart grid can be used as power supply system. EV charging infrastructure can be adopted at smart grid as power load. The charging infrastructure operator has a role of identification, monitoring \& control of charging system. Several ancillary services can be provided through charging infrastructure operator. Figure 2 shows configuration of EV charging infrastructure. Figure 3 is charging station located at HanNam University (HNU), Daejeon, Korea. 


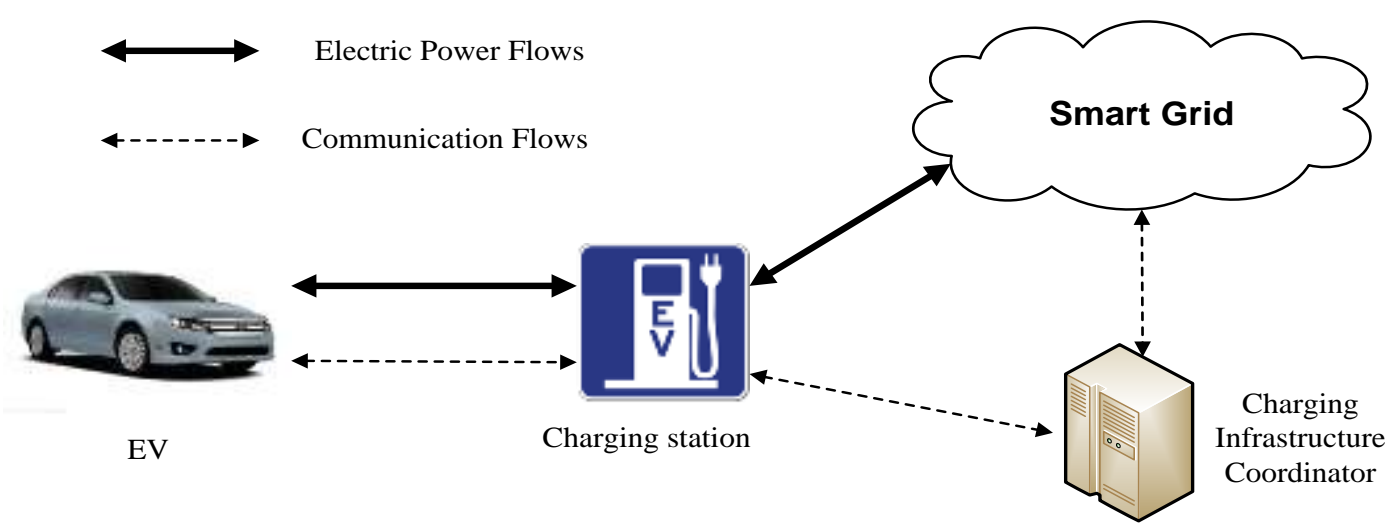

Figure 2. Configuration of EV Charging Infrastructure

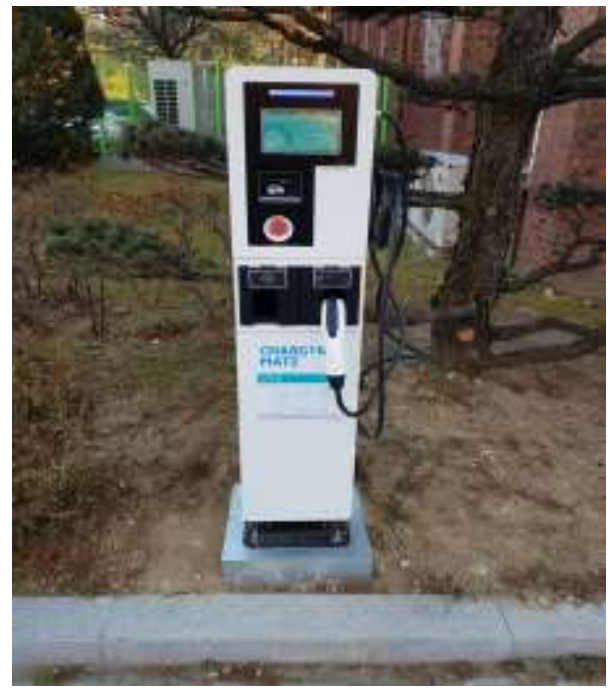

Figure 3. EV Charging Station in HNU

\section{Communication Technologies for EV Charging Infrastructure}

The Vehicle to Grid (V2G) technology is new concept which is firstly introduced in 1997 by Kempton and Letendre [11] of EVs in smart grid. With V2G EVs play a role of an electric load as well as distributed energy storage. The battery of the EV can provide electric power at peak load times or emergency with connection with smart grid. Therefore V2G technology [12] can help to improve reliability of the power grid. To use V2G technology several information of EV especially for battery information in EV and grid should be exchanged. On the one hand $\mathrm{V} 2 \mathrm{G}$ means just interface between vehicle and power grid. In figure 2 interfaces between EV and charging station is V2G. Therefore V2G network is communication network between EV and power grid.

\subsection{Communication Infrastructure for V2G Network}

Currently used EV charging station and EV exchange only limited information for charging with Pulse width Modulation (PWM). This information includes simply start and stop charging signal. Charging station deliverers the information of supplied amount of electric power informed form smart meter to the utility company 
for billing service and payment. However for smart charging and several ancillary services more sophisticated information is necessary.

The V2G network is communication links just between EV and charging station. Therefore it requires very short range for communication. The gateway in EV communicates with many devices such as ECU and BMS in EV with CAN (Controller Area Network). Through this gateway information for EV and charging can be exchanged between EV and charging station in power grid. The several communication technologies for short range are proposed for V2G network. For wireless technology Zigbee, Bluetooth and WiFi are expected to be used for communication between EV and charging station. Table 3 describes challenging wireless technology for V2G network.

Table 3. Wireless Technology for Communication for V2G

\begin{tabular}{ccccc}
\hline Technology & $\begin{array}{c}\text { Coverage } \\
\text { range }(\mathrm{M})\end{array}$ & $\begin{array}{c}\text { Data rate } \\
\text { (Mbps) }\end{array}$ & $\begin{array}{c}\text { Typical } \\
\text { Application }\end{array}$ & Band Licensed \\
\hline WiFi & $30-100$ & $5-100$ & Data Network & 2.4, and $5 \mathrm{GHz}$ \\
Bluetooth & $5-30$ & 3 & $\begin{array}{c}\text { Entertainment } \\
\text { Sensing and } \\
\text { Monitoring }\end{array}$ & $\begin{array}{c}2.4 \sim 2.485 \mathrm{GHz} \\
2.4 \mathrm{GHz} \text { band }\end{array}$ \\
\hline
\end{tabular}

The standard for vehicle to infrastructure (V2I) interface, ISO/IEC 15118[13] has been discussed from late 2000. This standard specifies the communication protocol between Electric Vehicle Communication Controller (EVCC) in EV and Supply Equipment Communication Controller (SECC) in charging station or in smart grid. The ISO/IEC 15118 has suggested to use Power Line Communication (PLC) for V2G interface. The ISO/IEC 15118 adopts two PLC technologies for V2G communication:

- HomePlug Green PHY

- G3- PLC

The HomePlug Green PHY (HomePlug GP) [14,15] is technology for supporting Smart Grid application at residence environment, especially for Home Area Network (HAN). This Homeplug GP was developed based on Homeplug AV specification [16]. The HomePlug GP reduces $75 \%$ of cost and power consumption comparing with HomePlug AV while meeting requirement of communication for Smart Grid [14]. Also this specification is interoperable with HomePlug AV and IEEE P1901.

The G3-PLC $[17,18]$ is specification of narrow band Power line with maximum data rate of $46 \mathrm{kbps}$. The OFDM is used for G3-PLC with frequency band from 10 to $490 \mathrm{KHz}$. G3-PLC has developed for smart grid application with environment of medium voltage power grid and transformer. Table 4 shows characteristics of HomePlug GP and G3-PLC specification.

Table 4. PLC Technologies for V2G Network

\begin{tabular}{ccccc}
\hline Technology & $\begin{array}{c}\text { Frequency } \\
\text { Band }\end{array}$ & Data rate & Modulation & Application \\
\hline $\begin{array}{c}\text { HomePlug } \\
\text { Green PHY }\end{array}$ & $2-28 \mathrm{MHz}$ & $\begin{array}{c}4,5 \text { and } 10 \\
\text { Mbps }\end{array}$ & OFDM & $\begin{array}{c}\text { Smart Grid applications } \\
\text { for Home Area Network }\end{array}$ \\
G3-PLC & $10-490 \mathrm{kHz}$ & $46 \mathrm{kbps}$ & OFDM & $\begin{array}{c}\text { Smart Grid applications } \\
\text { for Medium Voltage } \\
\text { Power Grid }\end{array}$ \\
\hline
\end{tabular}


The Communication infrastructure between charging station and central operator is well explained at several papers $[19,20]$. These communication technology for Smart Grid can be classified as Home area Network (HAN), Neighbor Area Network(NAN) and Wide Area Network (WAN) [21,22]. EV charging infrastructure can use communication infrastructure for AMI or use dedicated communication channel between charging station and central operator with WAN technology.

\section{Conclusion}

Development of Electric Vehicle technology has made rapid strides over the past few years. Many countries are boosting the electric vehicle market with policy and financial support. In contrast with conventional vehicle EV uses electric motor instead of internal combustion engine. Therefore EV does not exhaust any pollutant. However EV has still problem to solve of high cost and short driving range. The most important component of EV to effect on the driving range and cost of EV is battery. Currently EVs are considered as a way to prevent pollution of atmosphere and global warming. EV plays a role of just power load as well as distributed energy storage to use battery in EV for efficient power generation and consumption in Smart Grid. This concept is referred as Vehicle to Grid (V2G) technology. To integrate EV charging infrastructure at smart power grid several factors should be considered. One of most important component for integration of EV infrastructure is communication between EV and central operator. Information exchange between central operator and power grid can increase the reliability of the power grid with renewable energy resources and also support more efficient charging scheme for user of EVs. This paper introduces technologies for EV and EV charging infrastructure. Also communication technologies for V2G interface and smart grid are also discussed.

\section{Acknowledgements}

This paper has been supported by the 2017 Hannam University Research Fund.

\section{References}

[1] X. Fang, S. Misra, G. Xue and D. Yang, "Smart Grid - The New and Improved Power Grid: A Survey", IEEE Communications Surveys \& Tutorials, vol., issue. 4, (2011), pp 944-989.

[2] V. C. Güngör, D. Sahin, T. Kocak, S. Ergüt, C. Buccella, C. Cecati and G. P. Hancke, "Smart Grid Technologies: Communication Technologies and Standards", IEEE Transactions On Industrial Informatics, vol. 7, no. 4, (2011), pp.529-539.

[3] National Institute of Standards and Technology. NIST framework and roadmap for smart grid interoperability standards, release 1.0, http://www.nist.gov/public affairs/releases/upload/smartgrid interoperability final.pdf. January 2010.

[4] J. Yong, V. Ramachandaramurthy, K. Tan and N. Mithulananthan, "A review on the state-of-the-art technologies of electric vehicle, its impacts and prospects", Renewable and Sustainable Energy Reviews, vol. 49, (2015), pp. 365-385.

[5] M.-W. Ryu1, J.-S. Yoon1, S.-S. Lee, K.-H. Won and K.-H. Cho, "A Service Framework and Communication Method for Exchanging Information between Electric Vehicles and EV Charging Infrastructure", Journal of the Korea Academia-Industrial cooperation Society, vol. 12, no. 6, (2011), pp. 2823-2829.

[6] http://www.datanews.co.kr/m/m_article.html?no=99241.

[7] J. García-Villalobos, I. Zamora , J.I. SanMartín , F.J. Asensio and V. Aperribay, "Plug-in electric vehicles in electric distribution networks: A review of smart charging approaches", Renewable and Sustainable Energy Reviews, no.38, (2014), pp.717-731.

[8] "Welcome to 2009, SAE Officially Approves New Fast-Charging Combo: Coupler Standard (SAE J1772) for Plug-In EVs | Inside EVs", Insideevs.com, 2017. Available: http://insideevs.com/welcome-to2009-saereleases-new-fast-charging-combo-coupler-standard-sae-1772-for-plug-in-evs/. 
[9] F. Mwasilu, J. John Justo, E.-K. Kim, T. D. Do and J.-W. Jung, "Electric vehicles and smart grid interaction: A review on vehicle to grid and renewable energy sources integration", Renewable and Sustainable Energy Reviews, no.34, (2014), pp. 501-516

[10] M. D. Galus, M. Gonzalez Vaya, T, Krause and G, Andersson, "The role of electric vehicles in smart grids", WIREs Energy Environment, vol.2, (2013), pp.384-400

[11] W. Kempton and S. E. Letendre, "Electric vehicles as a new power source for electric utilities", Transportation Research Part D, vol. 2, no. 3, pp. 157-175, (1997).

[12] T. Selim Ustun, C. R. Ozansoy and A. Zayegh, "Implementing Vehicle-to-Grid (V2G) Technology With IEC 61850-7-420", IEEE Transactions On Smart Grid, vol. 4, no. 2, (2013), pp. 1180-1187

[13] http://www.iso.org/iso/catalogue_detail.htm?csnumber=55366.

[14] White Paper, "HomePlug Green PHYтм 1.1, The Standard for In-Home Smart Grid, Powerline Communications : An application and technology overview".

[15] HomPlug Green PHY Specification released version 1.1.1.

[16] HomePlug Alliance, HomePlug AV Specification Version 2.0, January 2012.

[17] G3-PLC Alliance. Http://www.g3-plc.com.

[18] M. Hoch,“Comparison of PLC G3 and PRIME”, IEEE ISPLC, (2011), pp.165 169.

[19] E. Ancillotti, R. Bruno and M. Conti, "The role of communication systems in smart grids: Architectures, technical solutions and research challenges", Computer Communications, (2013), vol. 36, pp.1665-1697

[20] J. Gaoa, Y. Xiao, J. Liu a, W. Liang and C.L. Philip Chen, "A survey of communication/networking in Smart Grids", Future Generation Computer Systems, no.28, (2012), pp. 391-404

[21] Y. Ye, Q. Yi, H. Sharif and D. Tipper, "A Survey on Smart Grid Communication Infrastructures: Motivations, Requirements and Challenges", IEEE Communications Surveys \& Tutorials, vol. 15, no. 1, (2013), pp. 5-20.

[22] M. Kuzlu, M. Pipattanasomporn and S. Rahman, "Communication Network Requirements for Major Smart Grid Applications in HAN, NAN and WAN", Computer Networks, vol. 67, no. 4, (2014), pp.7486. 